\title{
Editorial
}

\section{Nanoengineering in the modern steel industry}

There is a growing current awareness of the potential benefits of nanoengineering in the modern steel industry, and may leading research and development institutes and companies are pursuing research in the area of nanostructured steels. In the industry, the term ultra-fine grained is generally used to describe steels with average grain sizes between 1 and $2 * \mu \mathrm{m}$ in diameter and the term submicron (submicrometre) structure to refer to grain sizes between 100 and $1000 * \mathrm{~nm}$. Until recently, effective processing techniques to reduce the grain size of these materials to less than $100 \mathrm{~nm}$ did not exist.

There are major difficulties in creating novel nanostructures that have a combination of properties appropriate for large scale applications. An important requirement is to be able to manufacture nanostructured components which are large in all dimensions. In addition, the material concerned must be cheap to produce if it is not to be limited to niche applications. Severe deformation by methods such as mechanical milling, equal channel angular processing and high pressure torsional straining has not succeeded in this respect. Although mechanical milling and alloying can produce powders containing nanosized grains, grain growth cannot effectively be suppressed during consolidation processes such as sintering and hot pressing. Therefore, processing bulk nanoscrystalline materials for structural applications still poses a big challenge, particularly in achieving an industrially viable process. The purpose of this special issue is to describe various processing strategies and alloy developments currently being explored in the modern steel industry that have the potential to create extremely strong and affordable nanostructured engineering steels.

Combining plastic deformation and phase transformation has been widely used in conventional thermomechanical processing of steels. The most successful example is controlled rolling, with accelerated cooling for plates of low carbon steels. In this process, the target of refinement is ferrite. The mechanisms of the microstructural refinement are recrystallisation of austenite, enhanced nucleation of ferrite from deformed (un-recrystallised) austenite under large supercooling, and inhibition of grain growth of the obtained ferrite. Microalloying with titanium and/or niobium and precise control of rolling conditions (temperature, reduction and pass schedule) have realised a minimum average grain size of $5 * \mu \mathrm{m}$. The fine grained plates exhibit 
excellent toughness, as well as high strength. In a number of research projects carried out in the late 1990s, the principle of controlled rolling was investigated thoroughly under more severe conditions. That is, the finishing rolling was carried out at a much lower temperature (approximately $500-700^{\circ} \mathrm{C}$ ) using greater one-pass reductions of more than $50 \%$. As a result, a 1* $\mu \mathrm{m}$ grain size was achieved on the laboratory scale. Hodgson et al. in this special issue explore the limits of structural refinement in current steels with a ferrite microstructure. ${ }^{1}$ They review recent work related to the development of ultra-fine ferrite through phase transformation, nanoscale and ultra-fine bainite, precipitation and cluster strengthening and bake hardening of steels. In that context, Seto and Matsuda describe the design concepts and properties of already commercialised high strength steel sheets developed by nanoengineering at JFE Steel Corporation. ${ }^{2}$ This work is an extraordinary example of the industrialisation of nano-particle strengthened steels through conventional thermomechanical treatment.

In the case of bainitic ferrite microstructures it is possible to move from ultra-fine to nanoscale by decreasing transformation temperature. A new generation of steels has been designed in which transformation at low temperature $\left(200-350^{\circ} \mathrm{C}\right)$ leads to a nanoscale microstructure consisting of extremely fine, 20-40 nm thick, plates of ferrite and retained austenite. ${ }^{3}$ These steels present the highest strength/toughness combinations ever recorded in bainitic steels $\left(\sim 2.5 * \mathrm{GPa} / 40 * \mathrm{MPa} * \mathrm{~m}^{1 / 2}\right)$. Sourmail et al. ${ }^{4}$ have investigated in-service properties of nanostructured bainitic steels specifically designed to provide bainite transformation within industrially acceptable times. Results have demonstrated that these new nanostructured steels exhibit exceptional rolling-sliding wear performances, as little as $1 \%$ of the specific wear rate of conventional bainitised $100 \mathrm{Cr} 6$ bearing steels, and promising fatigue performance for industrially produced material.

The new concept of nanostructured oxide dispersion strengthened (ODS) ferritic alloys shows great promise for use in high temperature energy systems, especially future fusion reactors. It is essential to understand the microstructural stability and mechanical behaviour of these steels when subjected to the aggressive operating conditions of advanced fusion reactors, which currently are not well characterised. It is in this context that the atomic scale evolution of nanostructured ODS ferritic alloys under high temperature and irradiation conditions is paramount. Miller et $a l^{5}$ describe in this special issue the complex, ultrafine grained microstructure of an advanced nanostructured ferritic alloy consisting of nanoscale precipitates of 
$\mathrm{Ti}(\mathrm{N}, \mathrm{O}, \mathrm{C}), \mathrm{Y}_{2} \mathrm{Ti}_{2} \mathrm{O}_{7} / \mathrm{Ti}_{2} \mathrm{YO}_{5}$ and $\mathrm{Ti}, \mathrm{Y}, \mathrm{O}$ enriched nanoclusters. These nanoclusters are highly tolerant to high dose irradiation at elevated temperatures. In another contribution, Capdevila et al. ${ }^{6}$ analyse the kinetics of Fe-rich $(\alpha)$ and $\mathrm{Cr}$-rich $\left(\alpha^{\prime}\right)$ phase separation during aging of $\mathrm{Fe}-\mathrm{Cr}-\mathrm{Al}$ oxide dispersion strengthened alloys with a combination of atom probe tomography and thermoelectric power measurements.

The main drawback of bulk nanoscrystalline materials is the lack of both ductility and thermal stability. It has been suggested that ultrafine grains are unable to accommodate high density of dislocations, which results in significant reduction in the strain hardening ability of ultra-fine grain metals. ${ }^{7}$ A practical approach to control instability is to obtain grain structures with a bimodal size distribution, where large grains preferentially accommodate strain and small grains confer high strength such that a combination of high strength and high ductility is obtained. Second, the bimodal grain size distribution allows significant strain hardening and inhibits localised deformation. In this respect, Misra et $a l^{8}{ }^{8}$ describe here the attributes of a promising phasereversion approach that results in nanometre/ultrafine grain structures in austenitic stainless steels characterised by high strength and high ductility. The approach involves severe cold deformation (45-75\%) of metastable austenite to produce martensite, which on annealing for short durations reverts to austenite via diffusional or shear mechanisms, depending on the chemical composition of the steel.

Metallic glasses based on the specialised formulation of ferrous alloys can be used as a precursor to develop a whole range of derived nanoscale structures. These amorphous steels can also be used in the form of powders to produce amorphous/nanocomposite thermally sprayed coatings to enhance the wear and corrosion resistance of engineering components. Branagan et al. ${ }^{9}$ of The NanoSteel Company provide an overview of the commercial development of bulk materials nanotechnology, which utilises devitrification to expand the process window within which it is possible to achieve nanoscale structure formation in industrial products. Strategies for using these nanostructured materials as either coatings or stand-alone monolithic components are critically dependent on the operable ductility/toughness mechanisms. Bulk structures consisting of nanoscale precipitates in a glass matrix, produced by spinodal decomposition, are reported to provide significant levels of global plasticity and usable ductility and can undergo deformation without runaway shear propagation. Examples are given of the industrial application of these technologies. 
In recent years, novel surface nanocrystallisation approaches have been developed to synthesise nanostructured surface layers on metallic materials by mechanical means, such as by surface mechanical attrition treatment (SMAT) and surface mechanical grinding treatment (SMGT). With these techniques, microstructures within a surface layer as thick as few hundred micrometres can be effectively refined, forming a nano-grained gradient structure. These treatments provide a simple, flexible and low cost approach to enhance the bulk properties of steels, without any change in the chemical composition. In the present issue, Lu and co-workers ${ }^{10}$ demonstrate that the production of a nanostructured surface layer on a rod sample of a martensite stainless steel by SMGT significantly enhances the torsion fatigue strength of the bulk material. This improvement is attributed to the formation of a nanoscale grain structure with a hard surface layer and a high structural homogeneity.

The development of modern nanostructured steels requires multiple characterisation techniques (e.g. TEM/STEM, 3DAP, X-ray/neutron diffraction) and modelling and simulation tools (e.g. first principles calculations, Monte Carlo methods, cluster expansions, molecular dynamics, multiscale irreversible thermodynamics ${ }^{11}$ ) to investigate phase transformations at the atomic scale, the nature of nano-sized precipitates, nanoscale highly deformed surface layers ${ }^{12}$ and the deformation behaviour of nanocrystalline steels. The complementary nature of these experimental techniques, as well as the combination of experimental techniques with modelling and simulation, provide powerful synergies. The papers included in this special issue emphasise studies where multiple techniques and/or computational materials science tools have been coupled to study, at the atomic scale, the complex process related to precipitation/cluster formation and alloying effects on phase transformations in steels.

Readers are strongly encouraged to read the full text of these stimulating articles.

\section{Dr Francisca G. Caballero and Dr Carlos Capdevila}

Guest Editors

Spanish National Center for Metallurgical Research (CENIM-CSIC), Madrid, Spain

\section{References}

1. P. D. Hodgson, I. B. Timokhina and H. Beladi: 'Multiscale microstructure engineering of steels', Mater. Sci. Technol., 2013, 29, xxxx-xxxx. 
2. K. Seto and H. Matsuda: 'Application of nanoengineering to research and development and production of high strength steel sheets', Mater. Sci. Technol., 2013, 29, xxxx-xxxx.

3. F. G. Caballero, H. K. D. H. Bhadeshia, K. J. A. Mawella, D. G. Jones and P. Brown: 'Very strong low temperature bainite', Mater. Sci. Technol., 2002, 18, 279-284.

4. T. Sourmail, F. G. Caballero, C. Garcia-Mateo, V. Smanio, C. Ziegler, M. Kuntz, R. Elvira, A. Leiro, E. Vuorinen and T. Teeri: 'Evaluation of potential of high Si high C steel nanostructured bainite for wear and fatigue applications', Mater. Sci. Technol., 2013, 29, xxxx-xxxx.

5. M. K. Miller, C. M. Parish and Q. Li: 'Advanced oxide dispersion strengthened and nanostructured ferritic alloys', Mater. Sci. Technol., 2013, 29, xxxx-xxxx.

6. C. Capdevila, J. Chao, J. A. Jimenez and M. K. Miller: 'Effect of nanoscale precipitation on strengthening of ferritic ODS Fe-Cr-Al alloy', Mater. Sci. Technol., 2013, 29, xxxx-xxxx.

7. E. Ma: 'Instabilities and ductility of nanocrystalline and ultrafine-grained metals', Scripta Mater., $2003,49,663-668$.

8. R. D. K. Misra, J. S. Shah, S. Mali, P. K. C. Venkata Surya, M. C. Somani and L. P. Karjalainen: 'Phase reversion induced nanograined austenitic stainless steels: microstructure, reversion and deformation mechanisms', Mater. Sci. Technol., 2013, 29, xxxx-xxxx.

9. D. J. Branagan, A. V. Sergueeva, S. Cheng, J. K. Walleser, T. F. Weznel, J. V. Costa, W. Kiilunen, B. E. Meacham and C. D. Tuffile: 'Strategies for developing bulk materials nanotechnology (BMN) into industrial products', Mater. Sci. Technol., 2013, 29, xxxx-xxxx.

10. H.W. Huang, Z.B. Wang, X.P. Yong, and K. Lu: 'Enhancing torsion fatigue behaviour of a martensitic stainless steel by generating a gradient nano-grained layer via surface mechanical grinding treatment', Mater. Sci. Technol., 2013, 29, xxxx-xxxx.

11. P. E. J. Rivera-Díaz-del-Castillo, K. Hayashi and E. I. Galindo-Nava: 'Computational design of nanostructured steels employing irreversible thermodynamics', Mater. Sci. Technol., 2013, 29, $x x x x-x x x x$.

12. J. Takahashi, Y. Kobayashi, M. Ueda, T. Miyazaki and K. Kawakami: 'Nanoscale characterization of rolling contact wear surface of pearlitic steel', Mater. Sci. Technol., 2013, 29, xxxx-xxxx. 